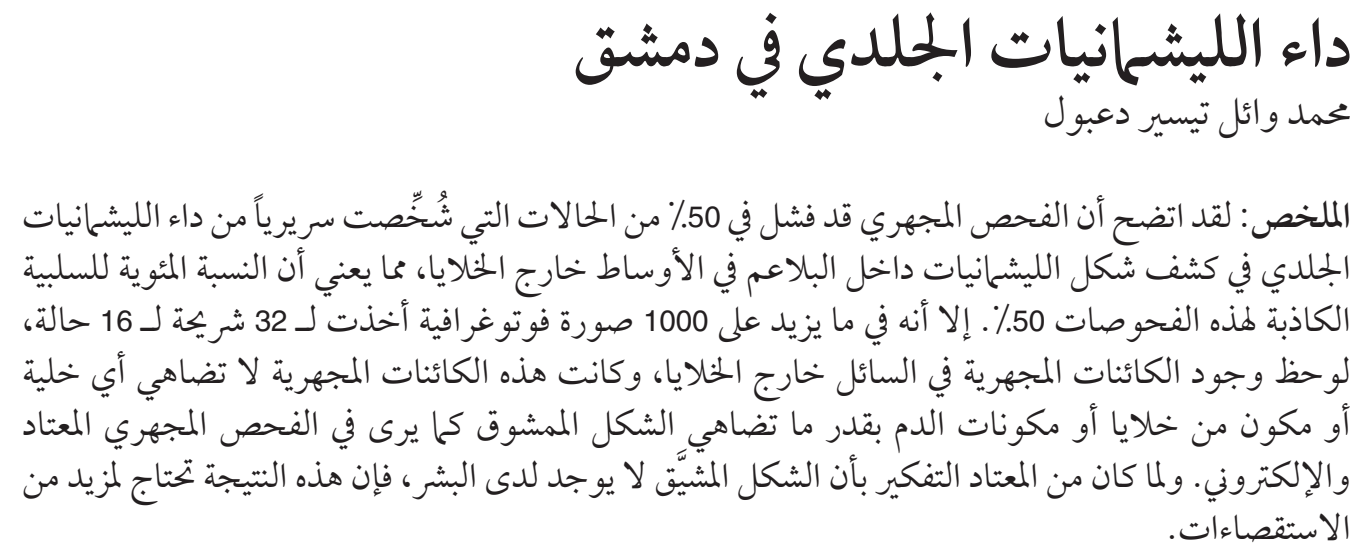

\title{
Cutaneous leishmaniasis in Damascus
}

ABSTRACT It was found that in $50 \%$ of clinically diagnosed cases of cutaneous leishmaniasis in Damascus, microscopic examination failed to detect the presence of the amastigote form of the parasite inside the macrophages or in the extracellular media, i.e. 50\% were false negative. However, in over 1000 photographs from 32 slides of 16 cases, the presence of microorganisms was noted in the extracellular fluid that did not match any of the known blood cells or components but did match the promastigote form as seen by general and electron microscopy. Since the promastigote form is not generally thought to be present in humans, this finding needs further investigation.

\section{Leishmaniose cutanée à Damas}

RÉSUMÉ On a constaté que dans $50 \%$ des cas de leishmaniose cutanée ayant fait l'objet d'un diagnostic clinique à Damas, l'examen microscopique n'a pas permis de détecter la présence de la forme amastigote du parasite à l'intérieur des macrophages ou dans le milieu extracellulaire, ce qui signifie que $50 \%$ des cas étaient des faux négatifs. Toutefois, sur plus de 1000 photos provenant de 32 lames correspondant à 16 cas, on a remarqué dans le fluide extracellulaire la présence de microorganismes qui ne correspondaient à aucune des cellules ni à aucun des composants sanguins connus, mais à la forme promastigote pouvant être observée grâce à la microscopie générale et électronique. La forme promastigote n'étant généralement pas censée être présente chez l'homme, il est nécessaire de poursuivre les recherches sur cette observation.

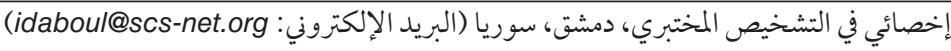
الاستلام: 07/05/27، القبول: 07/07/03 المختبرئ Mohamed Wael Tayseer Da'aboul, Laboratory Medicine Specialist, Damascus, Syrian Arab Republic. 
المقدمة

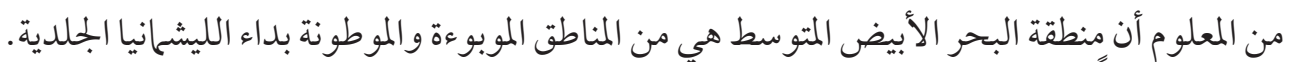

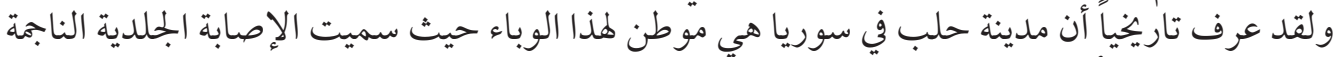

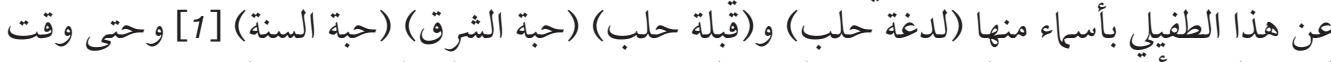

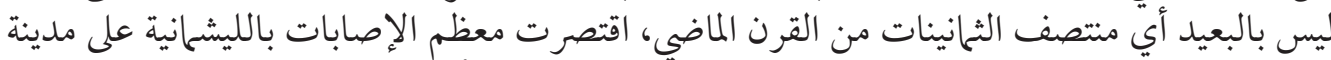

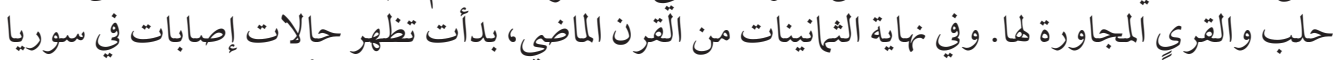

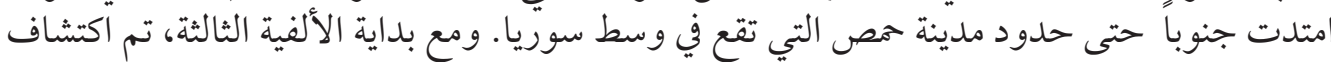

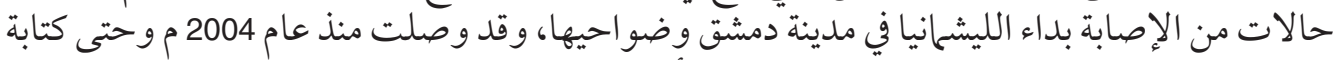

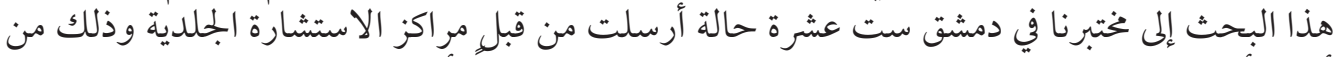

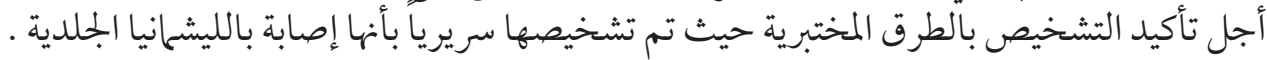

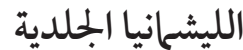

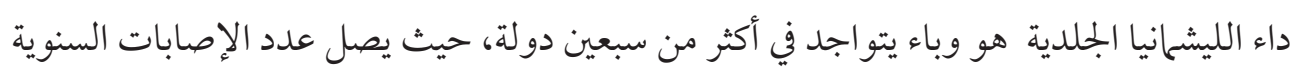

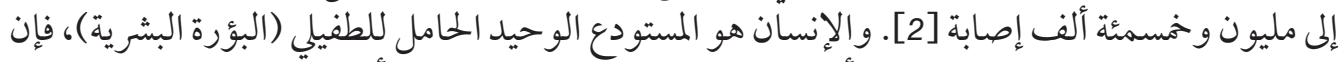

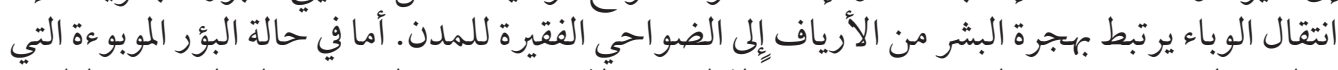

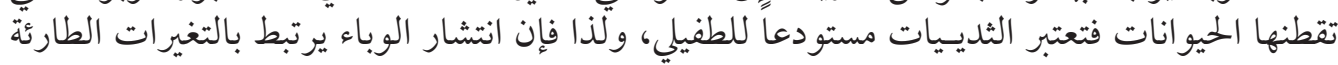

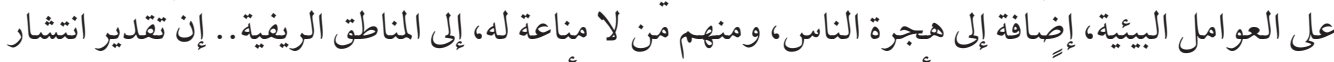

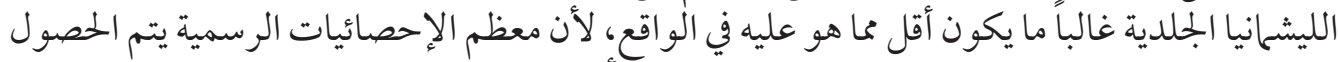

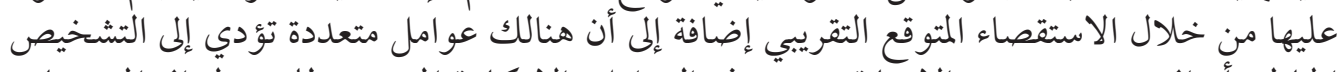

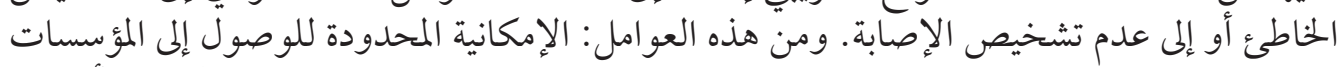

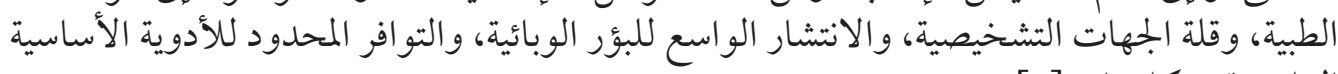
العلاجية بشكل دائم [2].

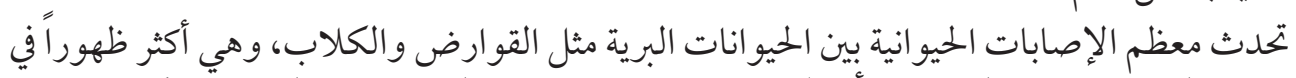

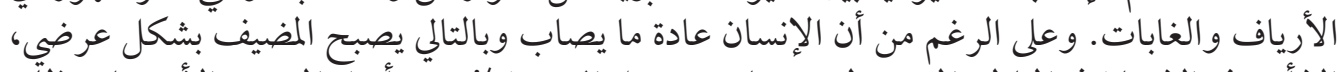

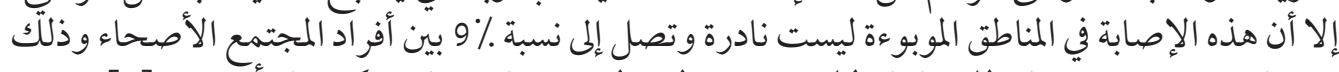

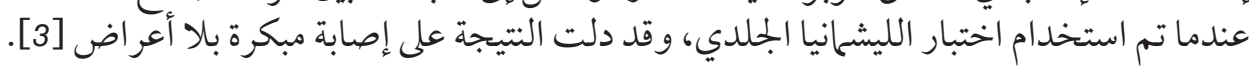

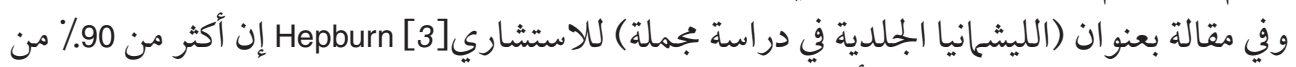

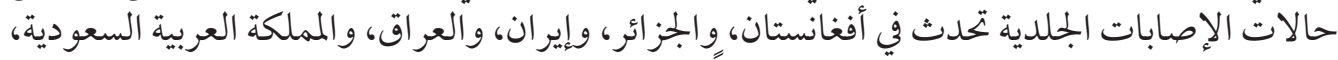

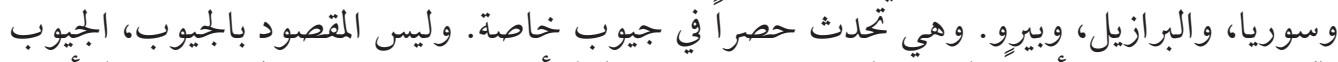

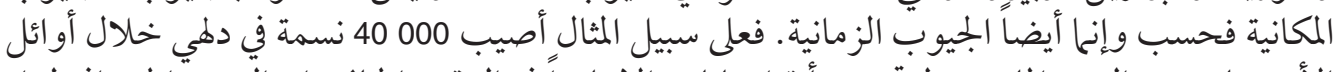

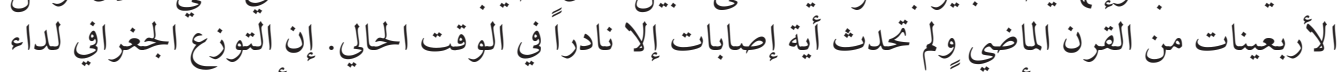

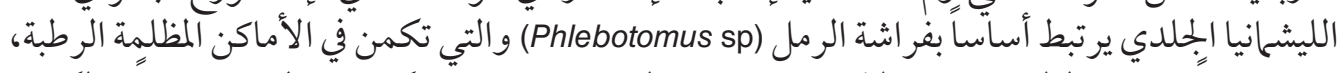

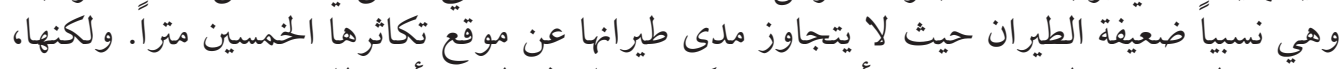

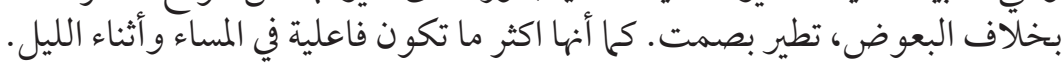

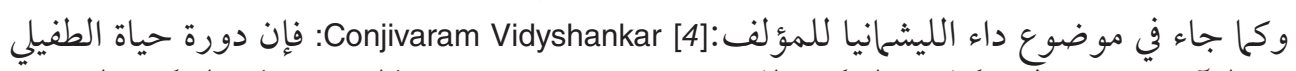

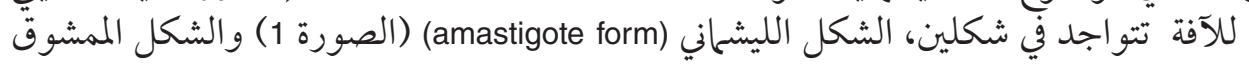


(الصورة 2). ويتو اجد الشكل الليشم) (الني عند البشر في حين أن الشكل الممشوق (promastigote form)

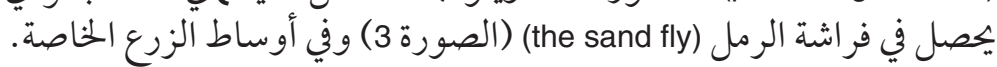

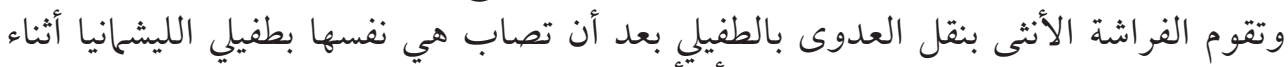

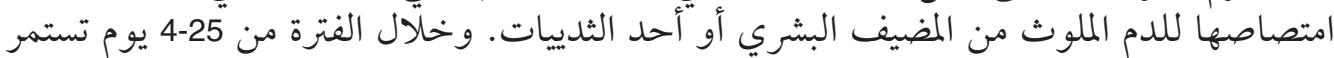

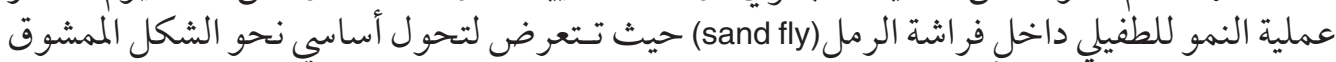

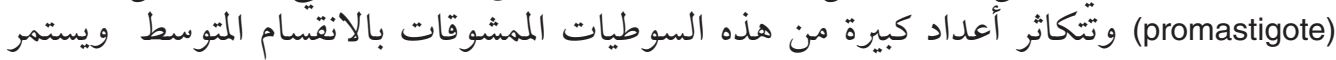

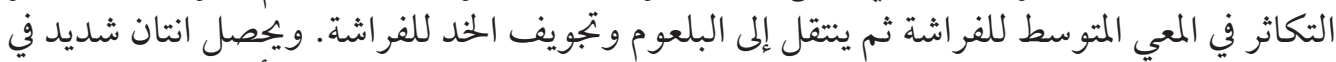

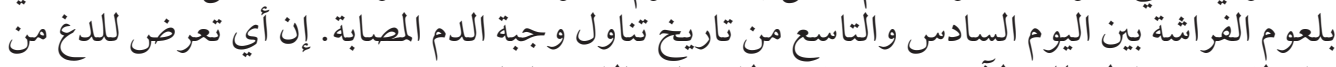

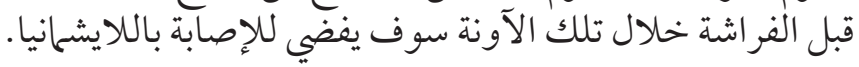

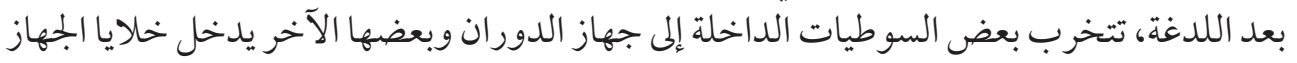

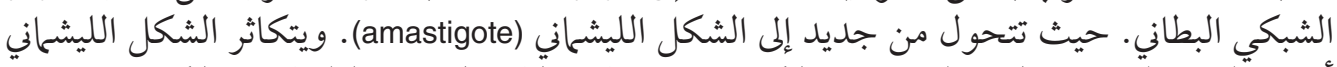

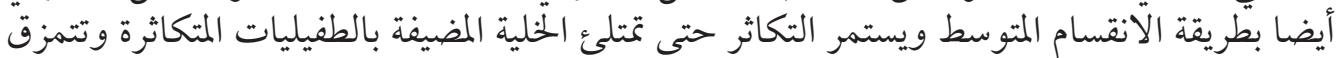

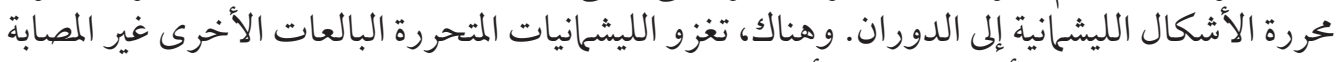

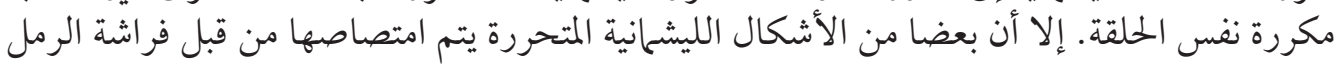
خلال وجبة التهامها للدم متمة بذلك دورة الخان حياتها.

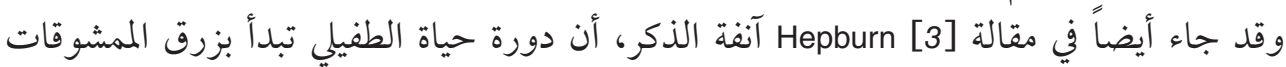

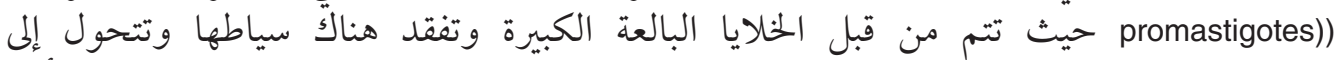

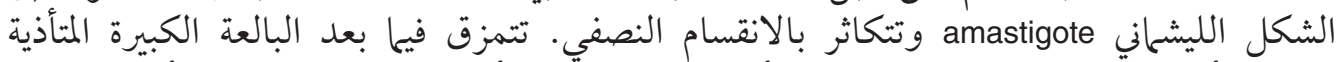

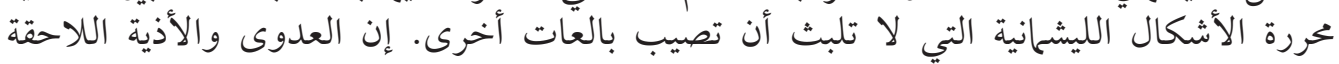

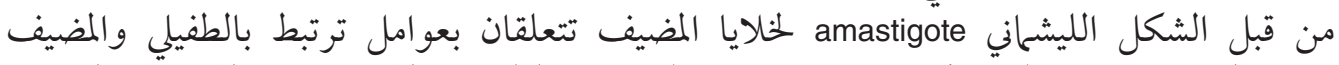

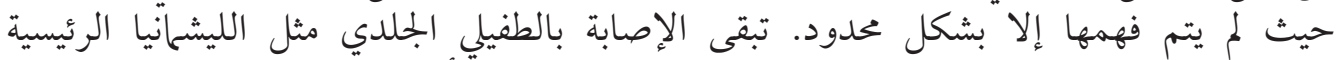
الجائة Leishmania major

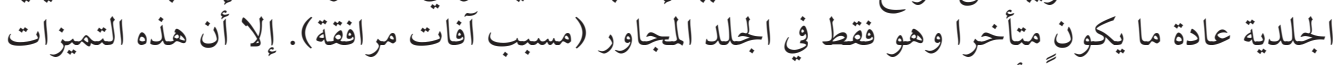

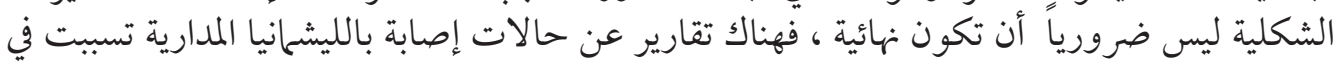
إصابات حشوية.

وكما جاء في موضوع (تقييم تشخيص الليشمانيا الجلدية باستخدام طريقة الفحص الفين المباشر

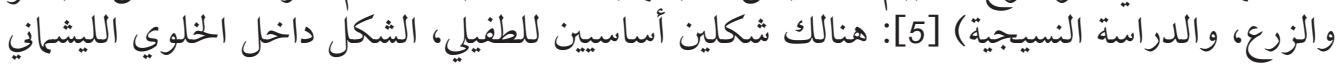
(amastigote) أساساً في الحشرة الحاملة.

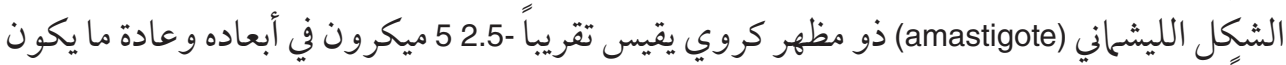

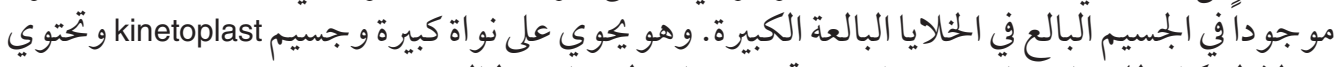

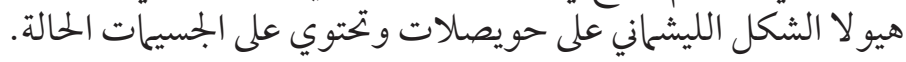

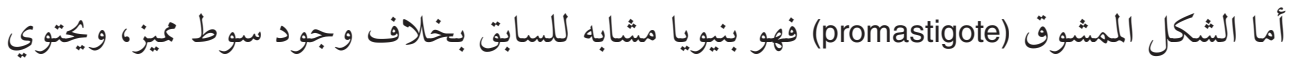

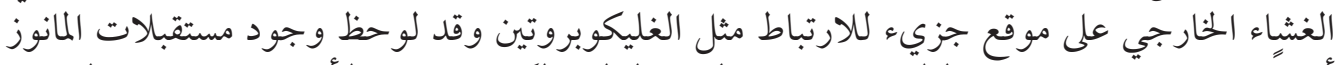

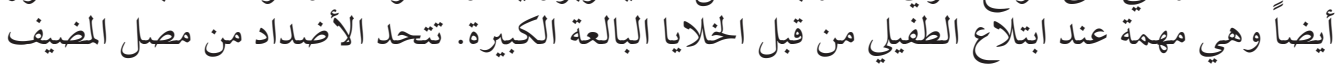




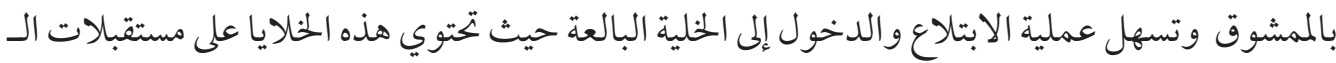

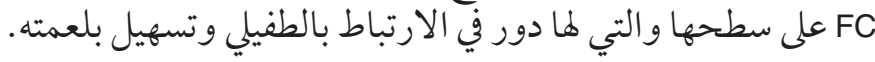

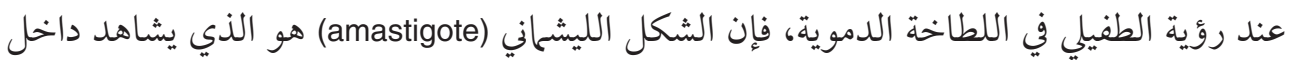

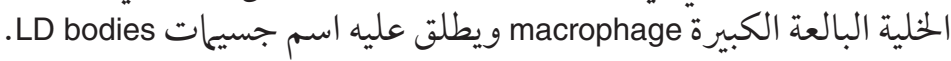

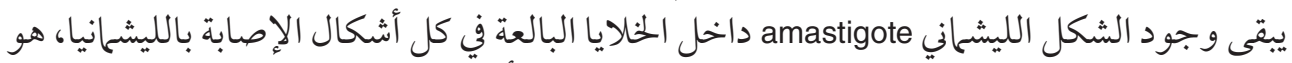

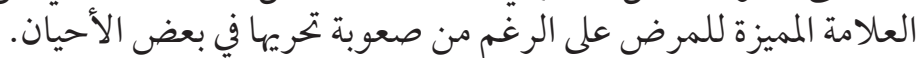

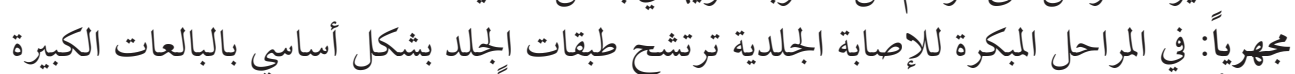

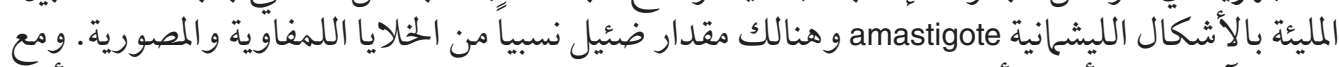

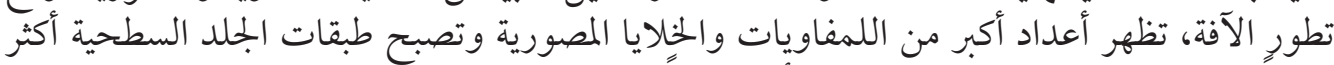

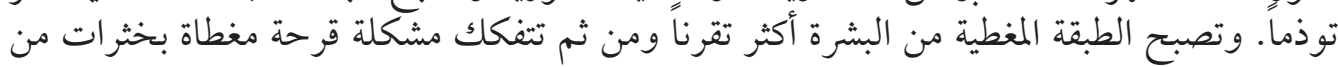

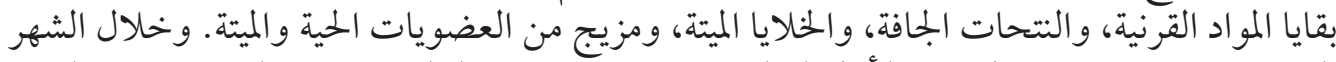

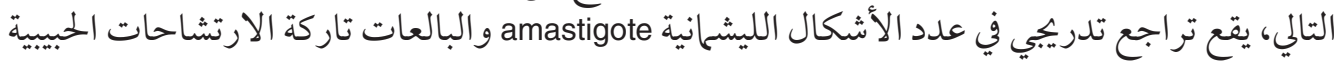

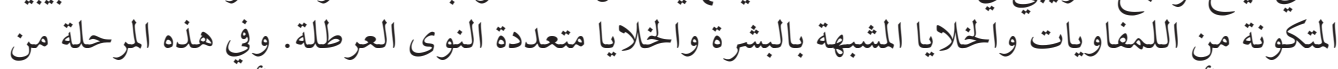

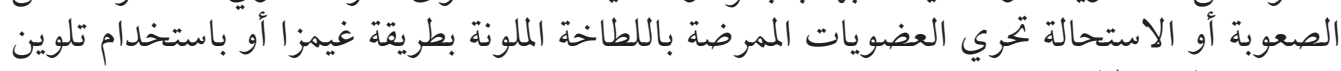

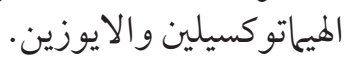

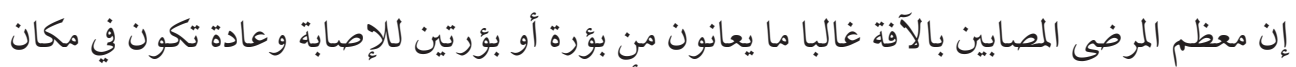

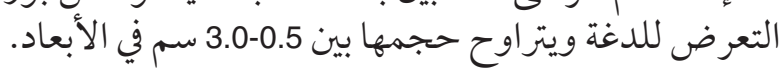

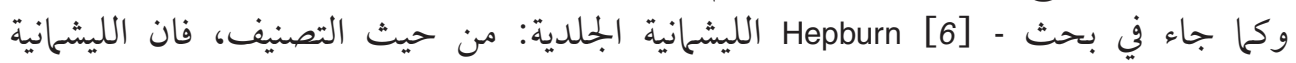

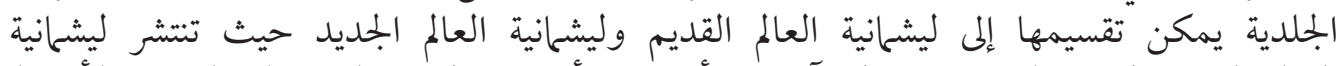

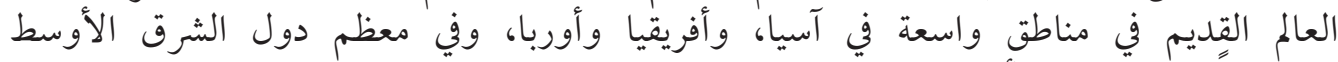

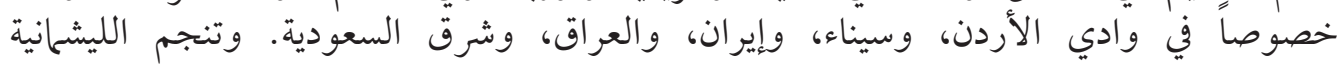

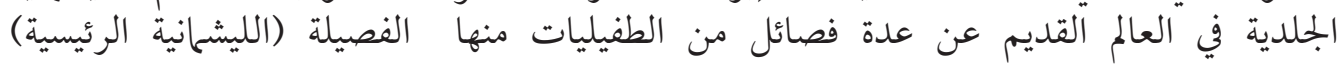
(Leishmania major)

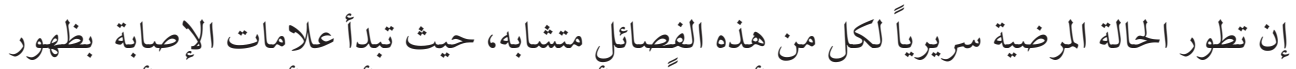

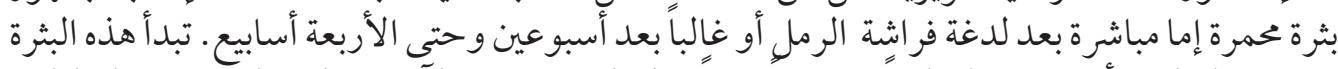

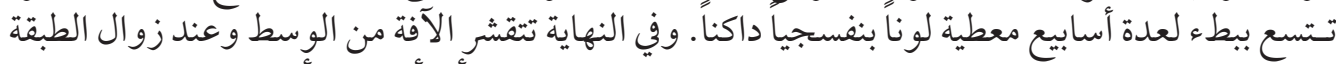

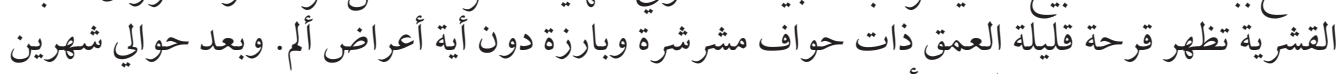

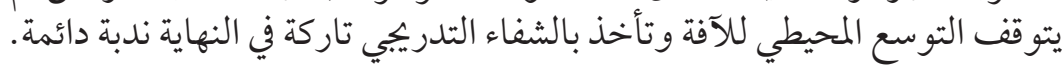

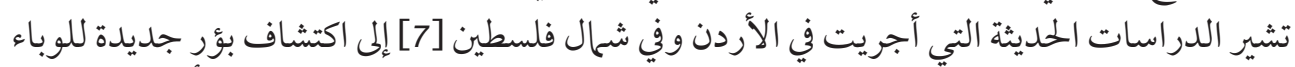

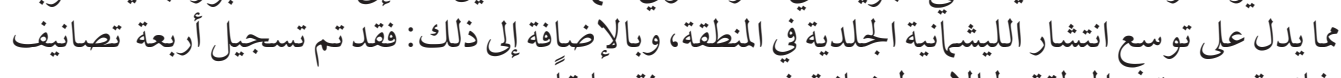

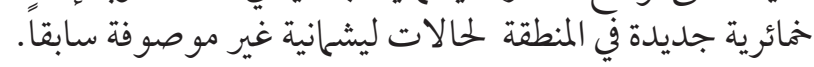
المدف من الدارسة

إن اكتشاف بؤر جديدة للإصابة في المناطق المجاورة لسوريا يستدعي منا متابعة لرصد انتقال وانتشار الليشمانية داخل القطر.

المجلة الصحية لشرق المتوسط، منظمة الصحة العالمية، المجلد الخامس عشر، العدد 0، 9.? 
إن الدراسات حول الليشمانية الجلدية تكاد تجمع على أن هنالك شكلين أساسيين للطفيلي: الشكل

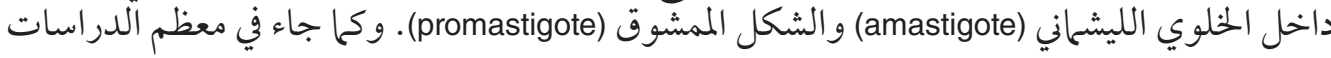

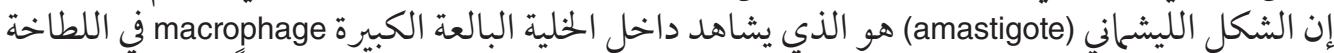

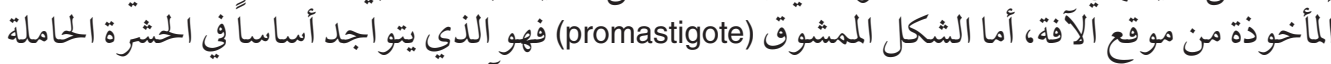

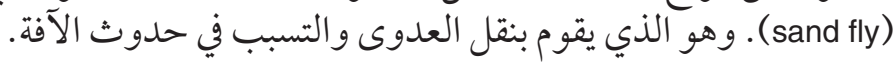

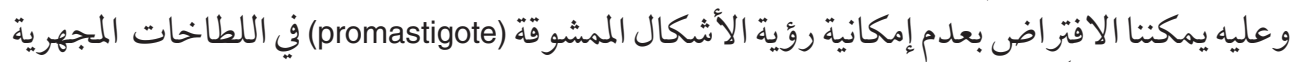

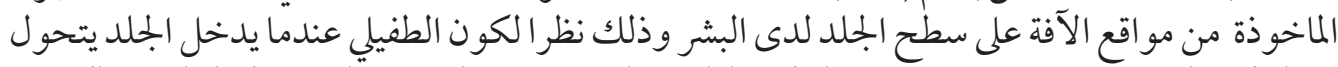

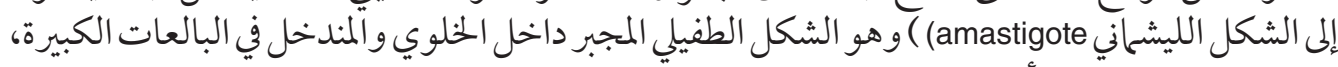

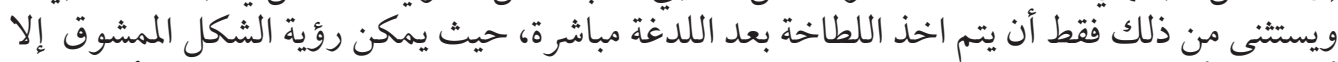

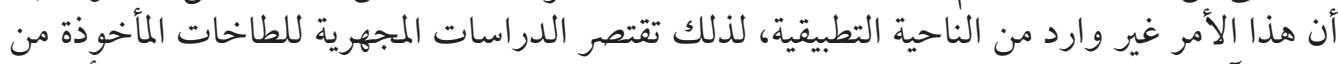

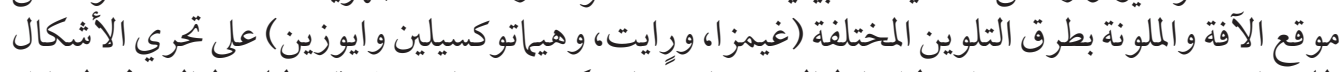

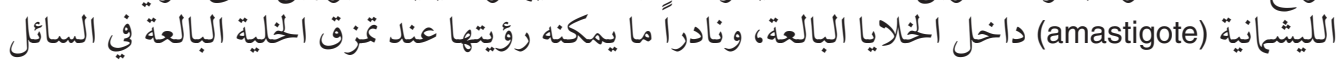

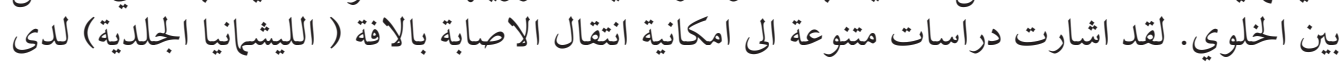

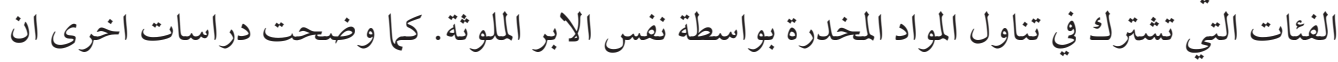

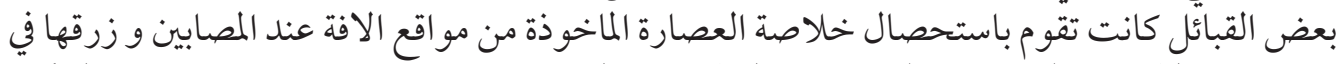

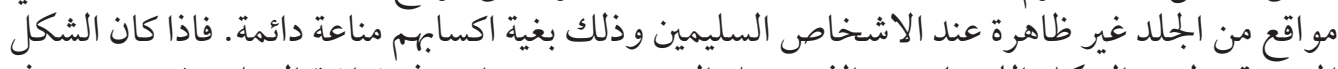

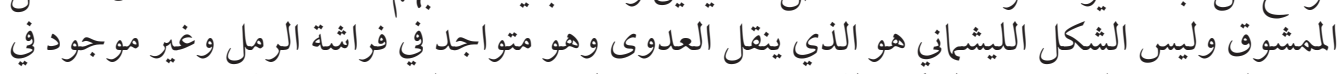

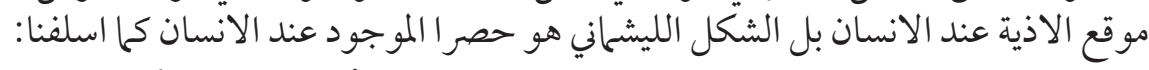

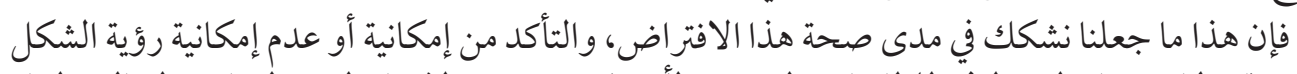

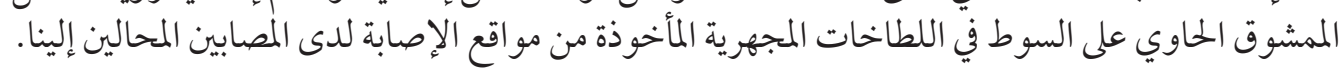

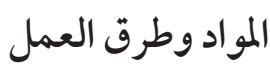

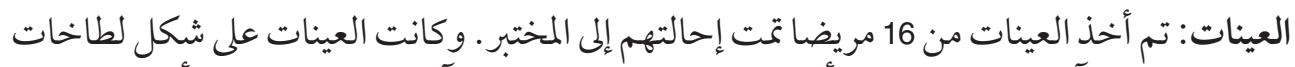

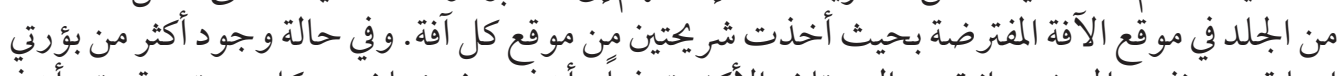

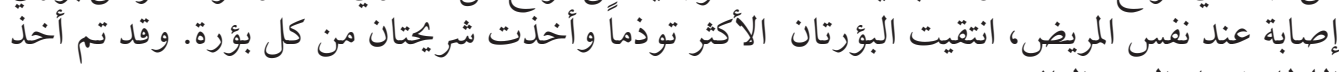

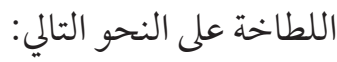

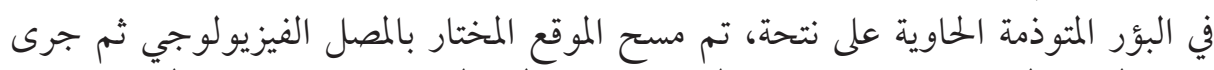

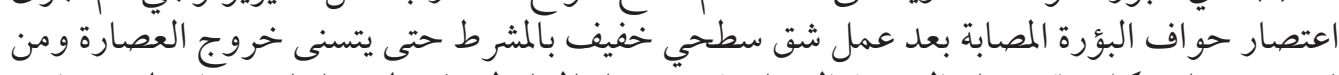

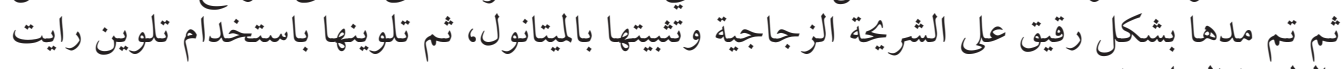
بالطريقة التقليدية.

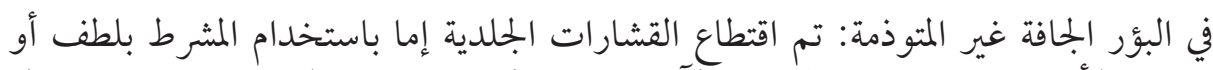

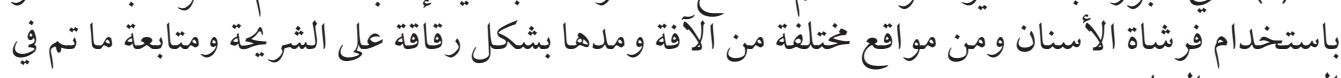

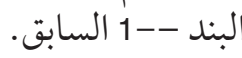
تم أخذ عدة صور مجهرية لكل حالة وصنفت على النحو التالي: (مثال): الحالة الأولى =1p،

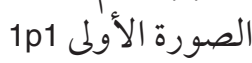


الصورة الثانية =1p2 ، الحالة الثانية = p2 الصورة الأولى، الحالة الثانية = 2p1 وهكذا إلى الحالة 16 p. وتم مقارنة الأشكال المجهرية للطفيلي بصور مرجعية مرقمة كمثال (1)، (2) بدون الحرف p.

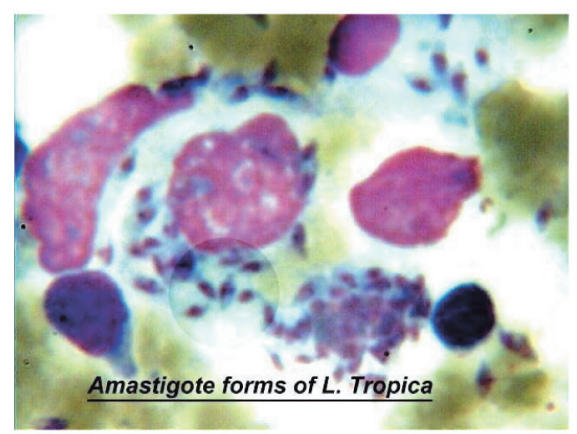

(1) الصورة

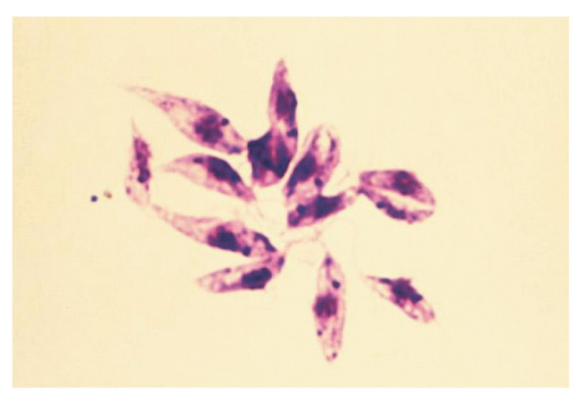

(2) الصورة

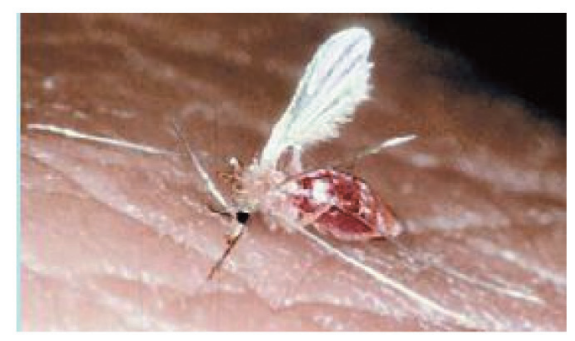

(3) الصورة 
يبين الجحدول (1) المصدر الجغر افي للعينات الست عشرة المستحصلة من دمشق والضواحي المجحاورة:

\begin{tabular}{|c|c|c|c|c|c|c|c|c|c|}
\hline حوران & مساكن & القدم & الميدان & المينبي & داريا & وصحضنايا & قردىيا & المزة & الموقع \\
\hline 1 & 1 & 1 & 1 & 2 & 2 & 2 & 4 & 2 & الإصابات \\
\hline
\end{tabular}

يبين الجلدول (2) تصنيف العينات وفقا لعدد البؤر الجلدية الملاحظة سريرياً عند كل مريض:

\begin{tabular}{|c|c|c|c|c|c|}
\hline 9 & 4 & 3 & 2 & 1 & عدالإلبؤر الجلدية \\
\hline 1 & 2 & 2 & 5 & 6 & عدد الحالات \\
\hline
\end{tabular}

يبين الجدول (3) توزع الشكل الليشحاني (amastigote) في الشرائح المجهرية للمرضى داخل أو

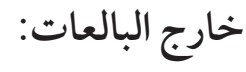

\begin{tabular}{|c|c|c|c|c|}
\hline موجود في اللطاخة داخل & البالعارج & داخل البالعات فقط & و وحيدة في اللطاخة & الشكل الليشماني \\
\hline $8 / 16$ & $1 / 16$ & $0 / 16$ & $4 / 16$ & عدد الحالات \\
\hline 50 & 6.25 & 0 & 25 & النسبة المئوية ٪\% \\
\hline
\end{tabular}


يبين الجدول (4) الأشكال الشبيهة بالممشوقة (promastigote) المكتشفة في الشرائح المجهرية للمرضى:

\begin{tabular}{|c|c|c|c|}
\hline متر افقاً مع الشكل & موجوداً في اللطاخة & وحيداً في اللطاخة & الأشكال الشبيهة \\
\hline $2 / 16$ & $7 / 16$ & $16 / 0$ & عدد الحالات \\
\hline 12.5 & 43.75 & 0 & النسبة المئوية ٪ \\
\hline
\end{tabular}

يبين الجمدول (5) الأشكال الشبيهة بالممشوقة ذات السياط (trypomastigote) المكتشفة في الثرائح

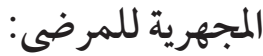

\begin{tabular}{|c|c|c|c|c|}
\hline 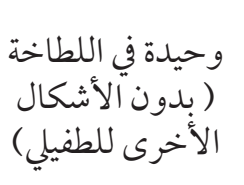 & الأشكال الشبييهة مترة & متر افقة مع الشكل الليشماني & موجودة في & 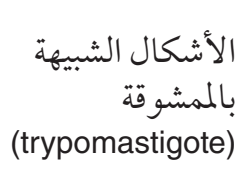 \\
\hline $3 / 16$ & $7 / 16$ & $4 / 16$ & $12 / 16$ & \\
\hline 18.75 & 43.75 & 25 & 75 & النسبة المئوية.٪ \\
\hline
\end{tabular}

يبين الجدول (6) النسب المئوية للأشكال الليشمانية الثلاثة في اللطاخة:

\begin{tabular}{|c|c|c|c|}
\hline الأشكال الشبيهة & الشكل الليشماني & الأشكال الشبيهة & الأشكال الليشمانية \\
\hline$\%$ \%3.75 & $\%$.50 & $\% 75$ & النسبة المئوية ٪\% \\
\hline
\end{tabular}




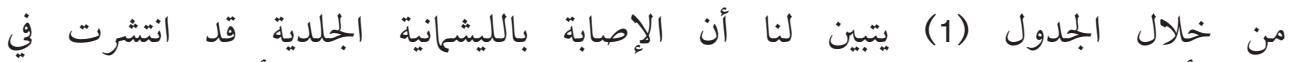

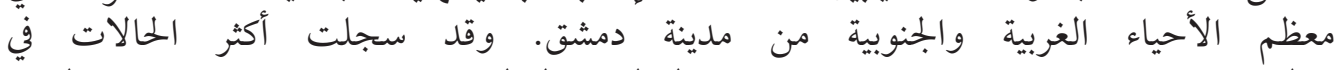

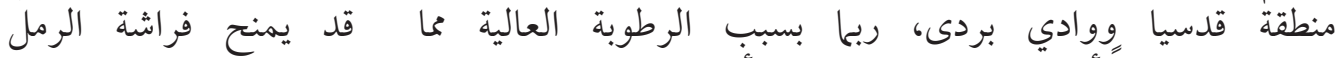

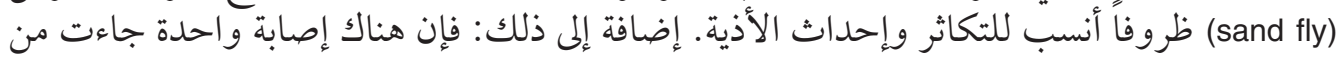

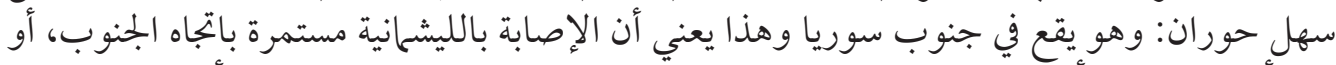

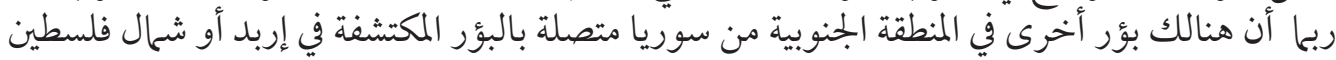

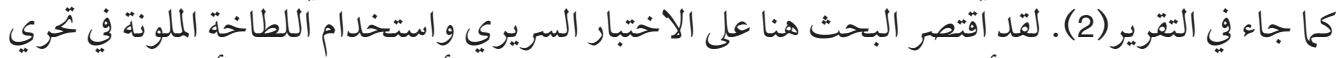

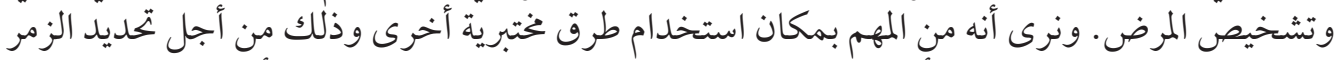

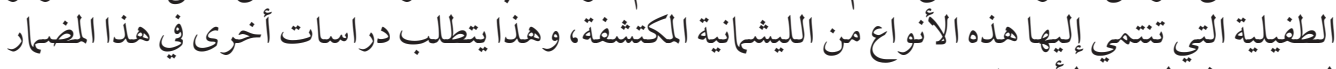

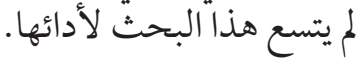

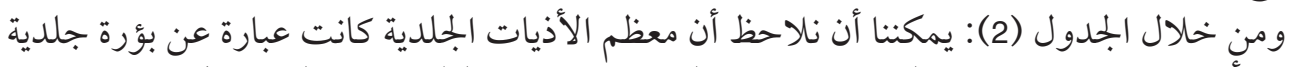

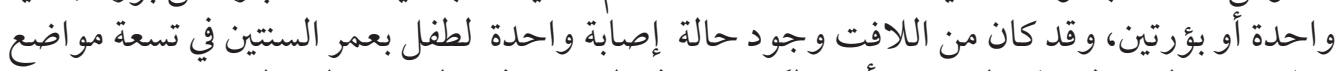

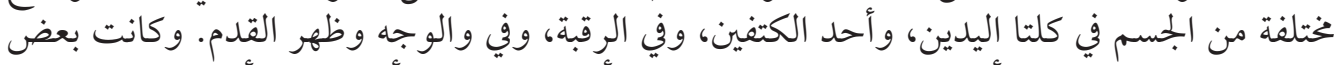

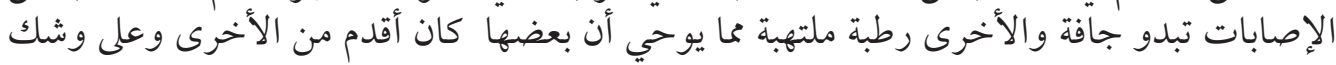

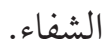

أما الجداول (3، 4، 5، و 6) فقد أرفقت معها الصور الموثقة التي صورتها للمحضر ات المجهرية وهي في ملف خاص مرفق بالبحث.

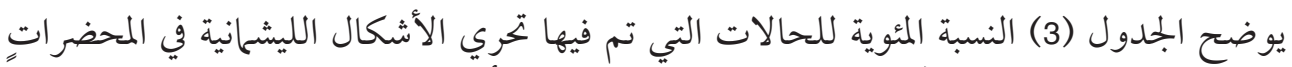

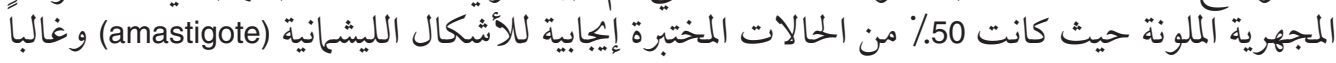

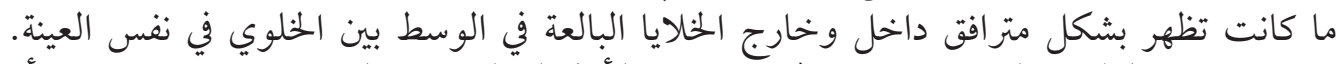

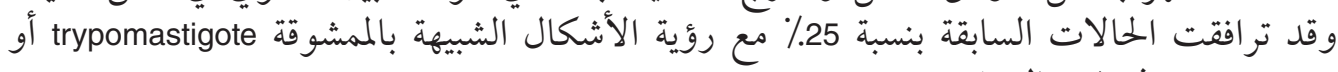
promastigote

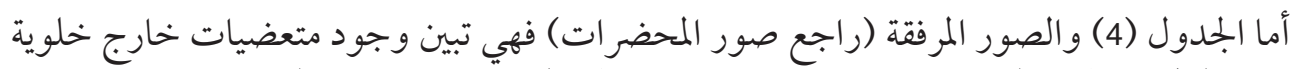

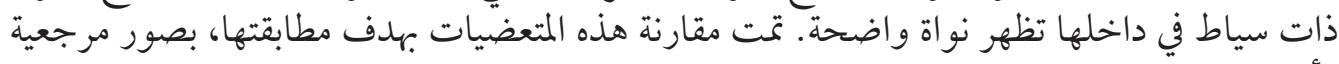

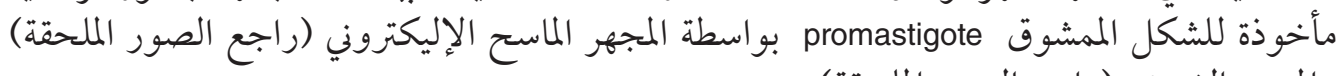

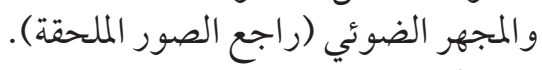

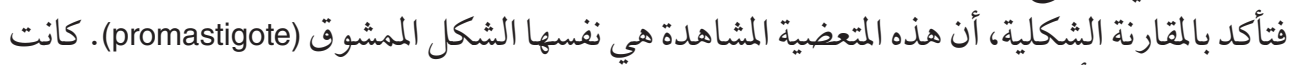

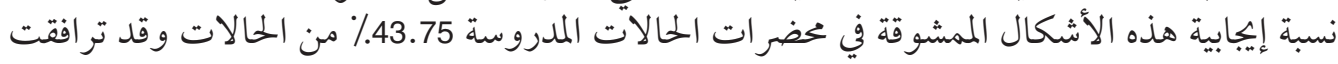

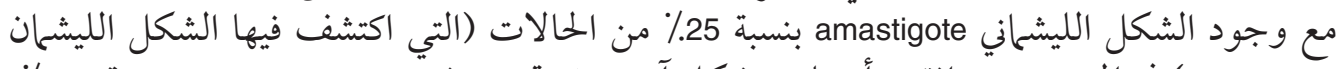
(amastigote 


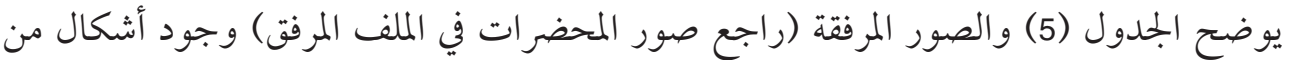

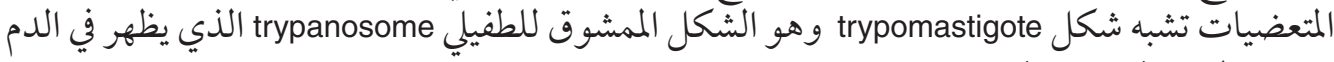

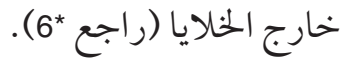

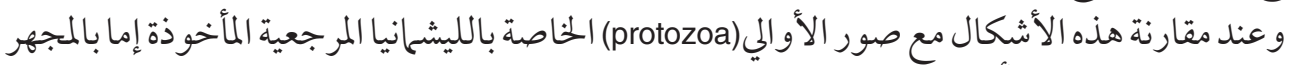

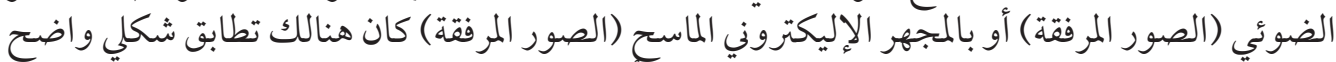

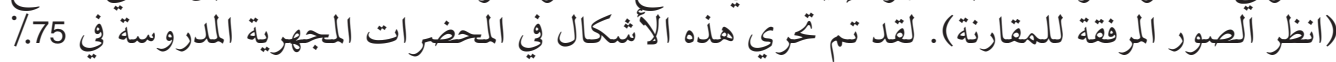

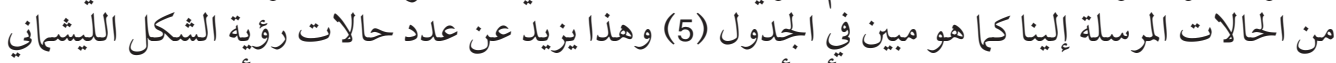
(amastigote)

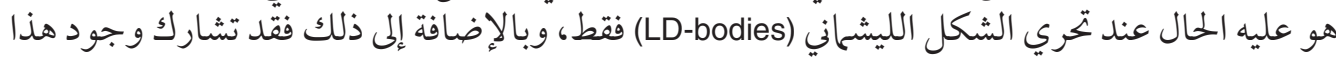

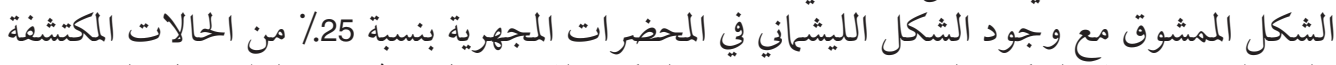

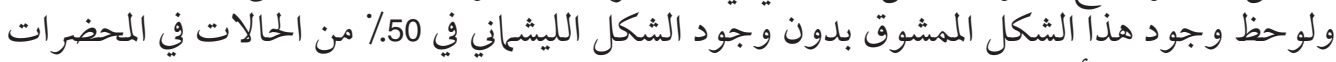

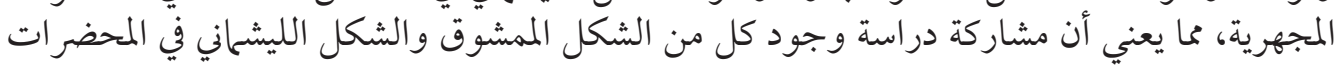

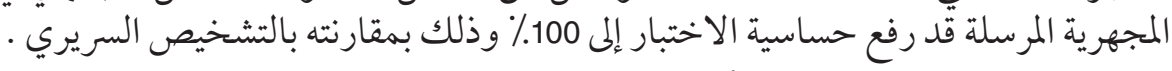

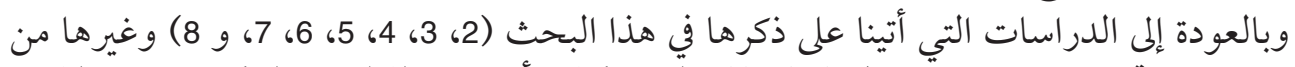

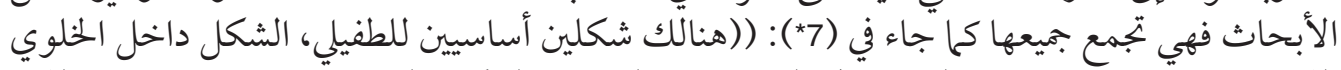

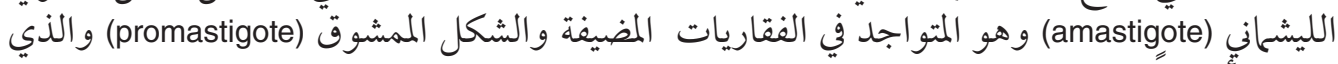

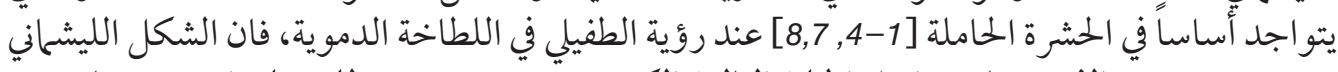

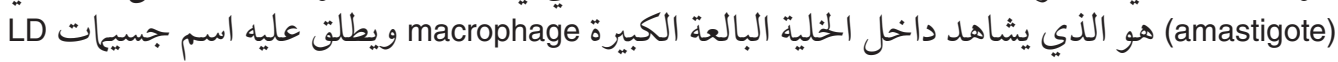

(( bodies

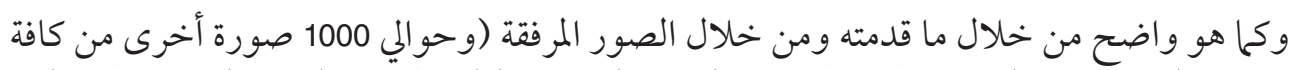

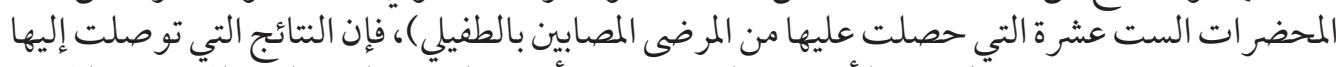

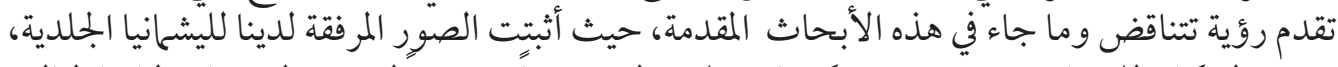

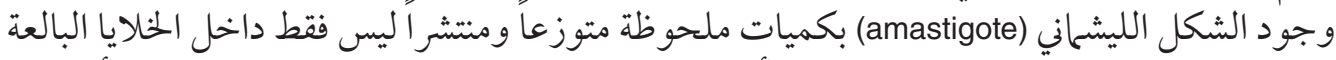

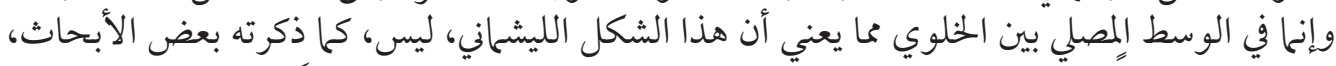

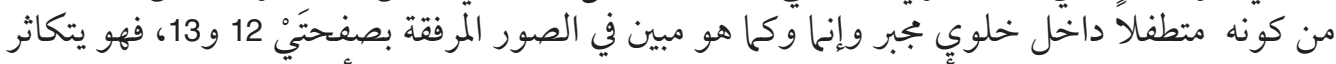

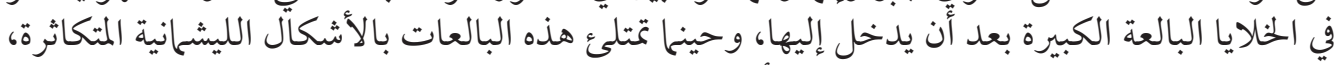

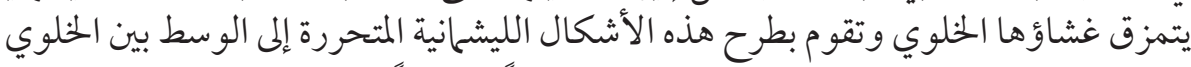

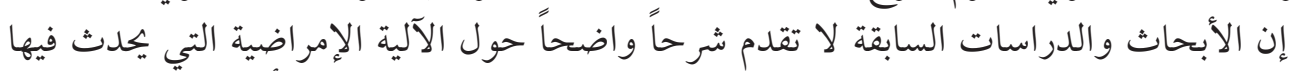

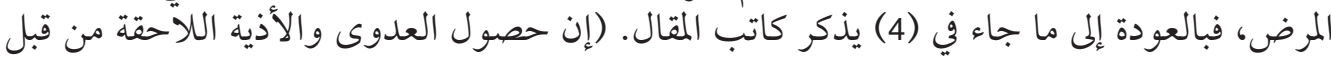

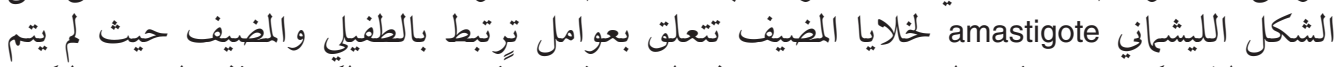

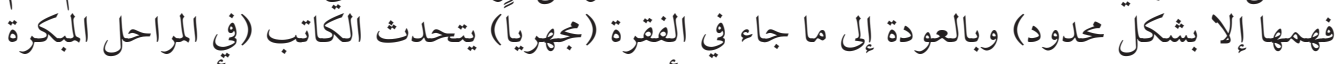

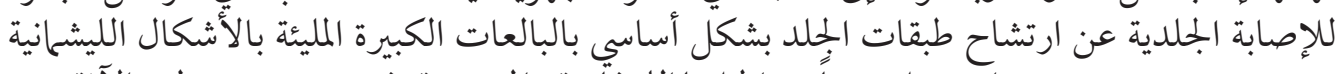
amastigote

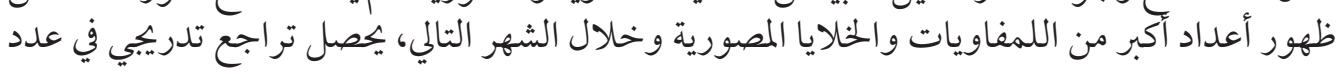




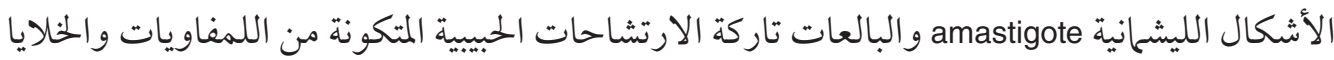

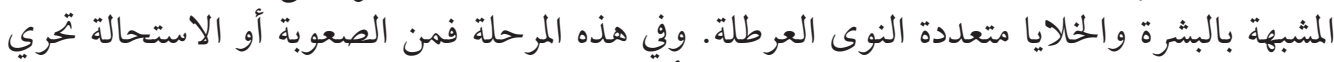

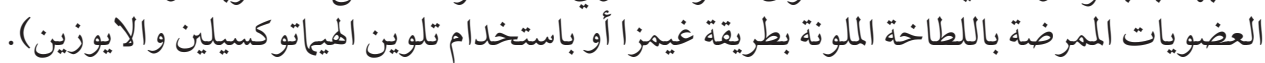

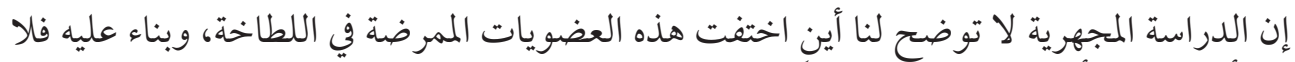

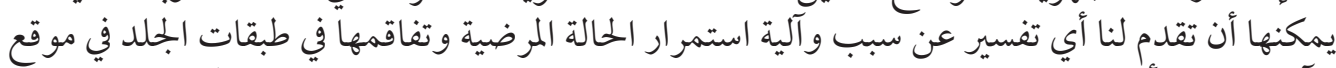

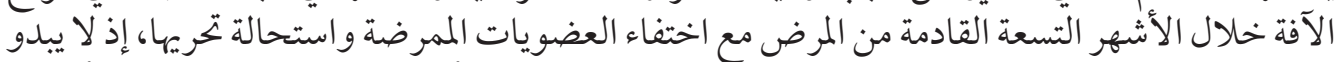

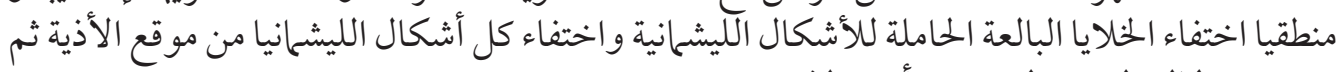

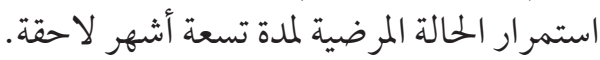

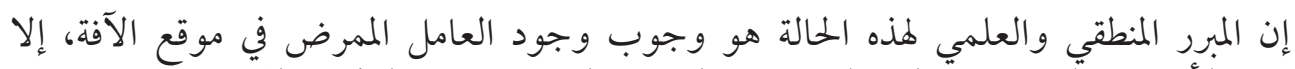

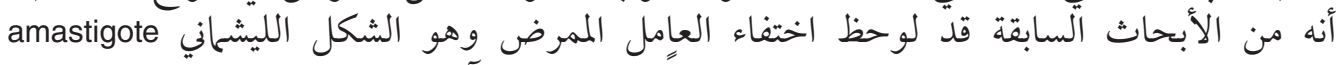

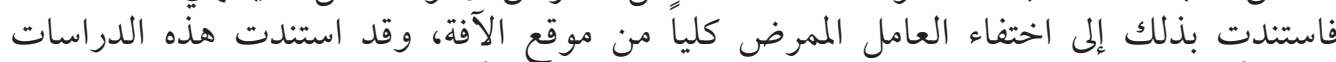

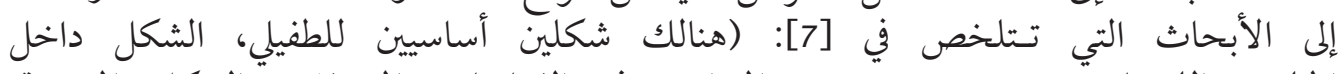

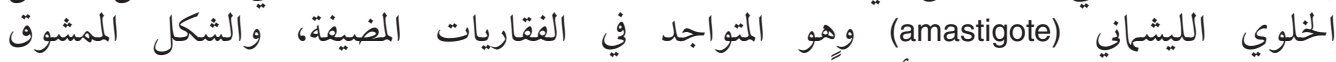

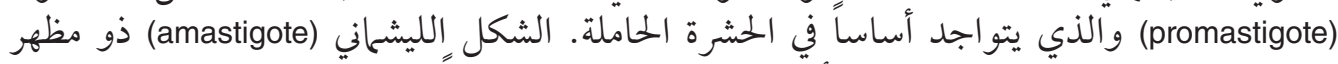

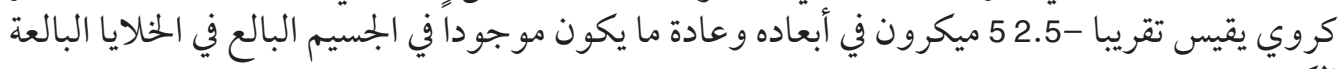
الكبيرة.

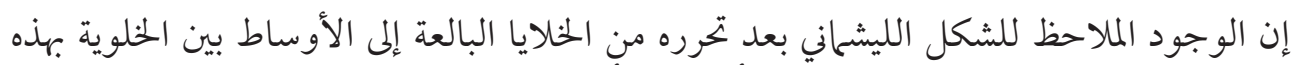

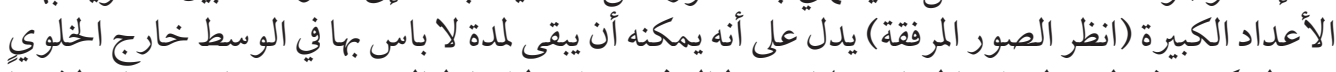

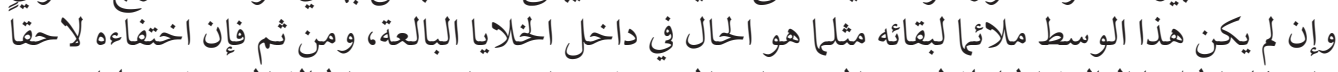

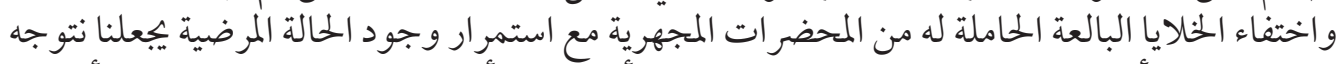

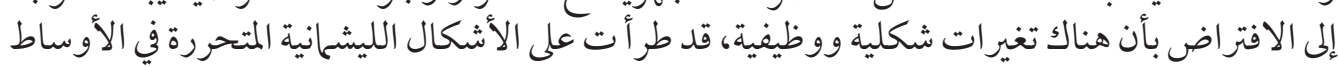

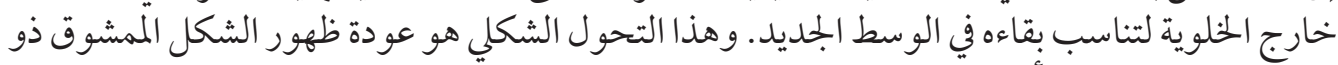

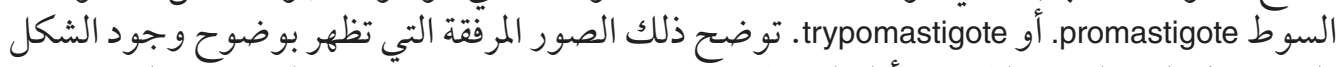

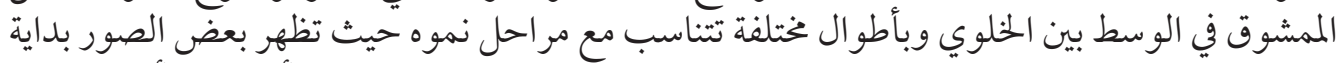

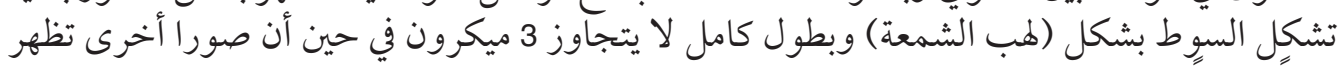

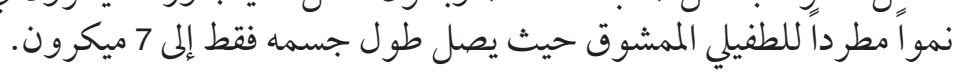

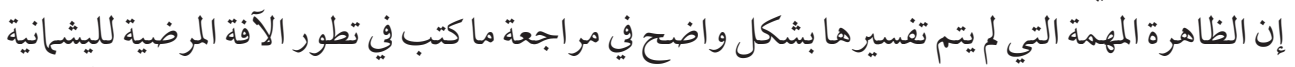

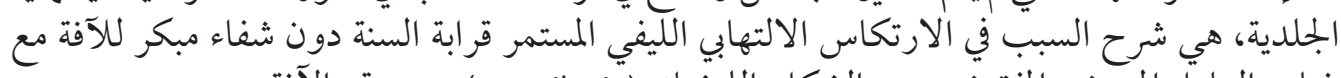

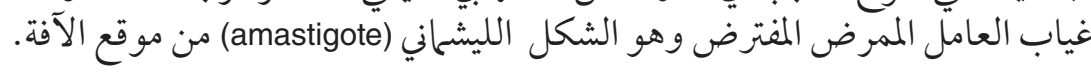

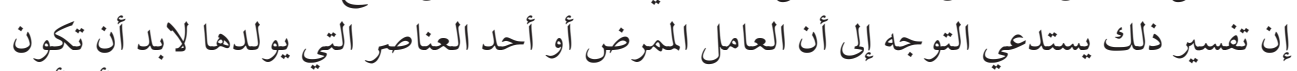

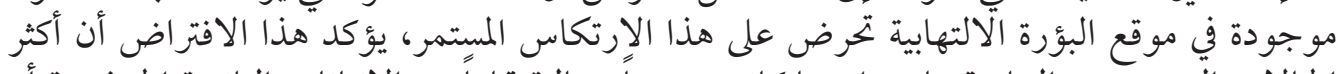

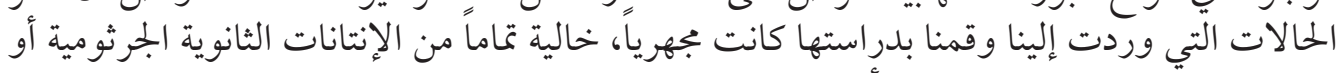

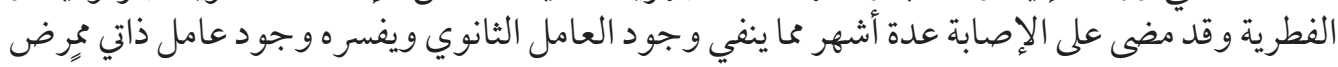

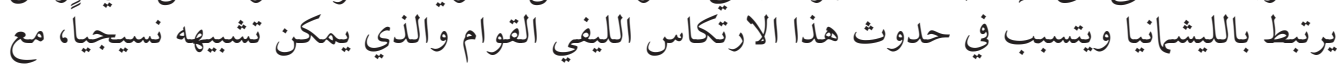




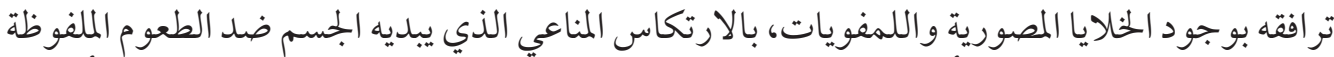

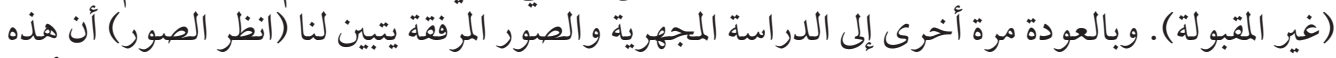

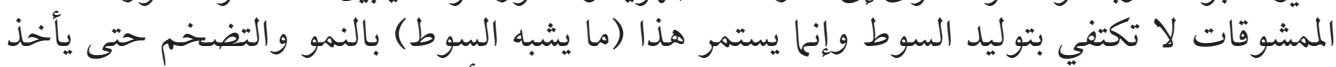

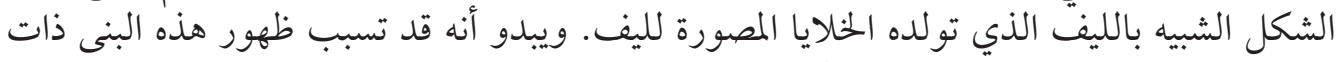

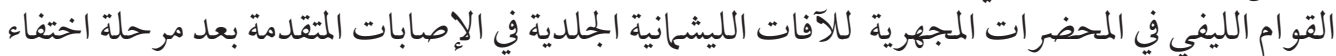

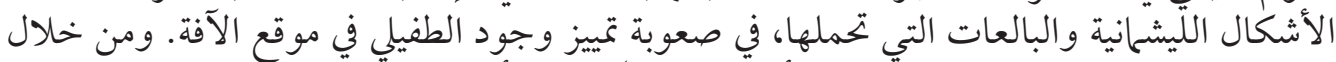

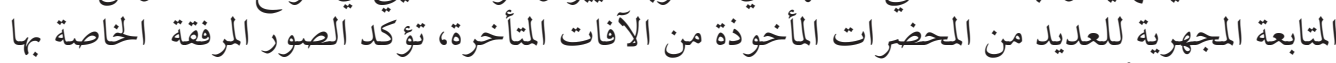

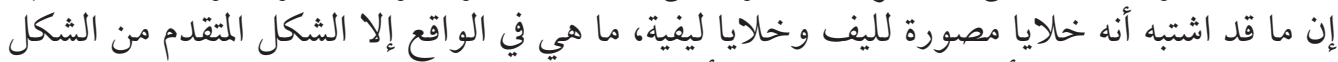

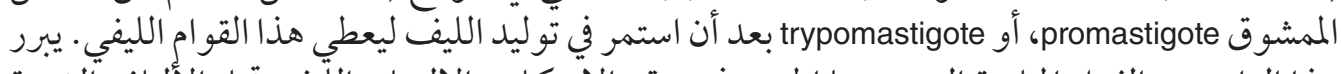

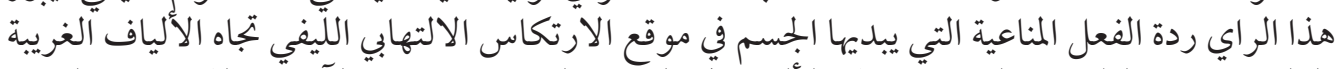

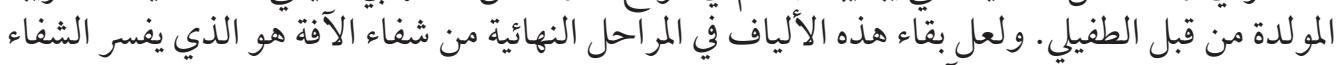

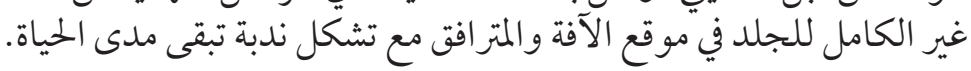

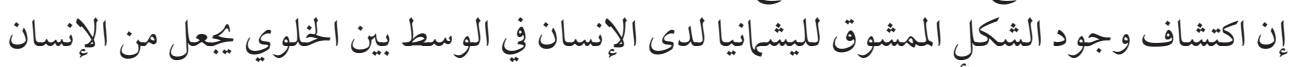

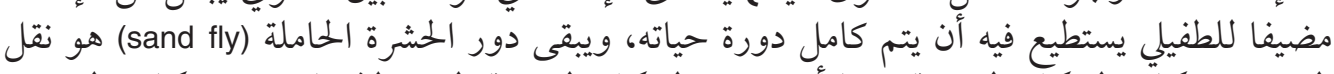

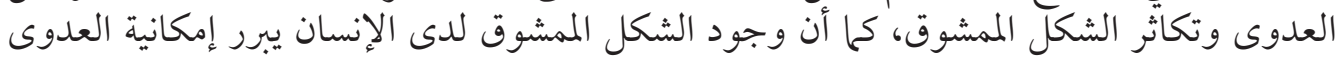

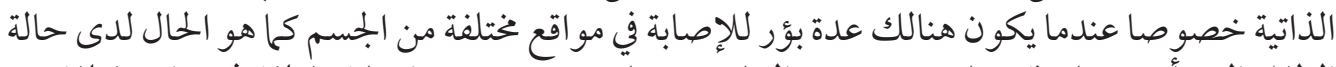

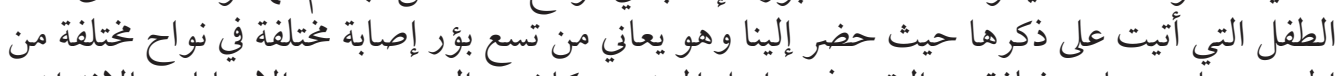

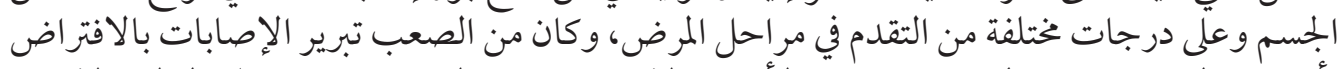

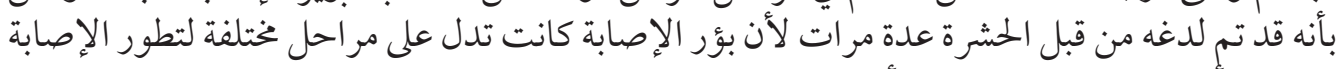

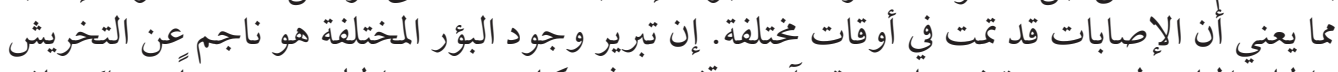

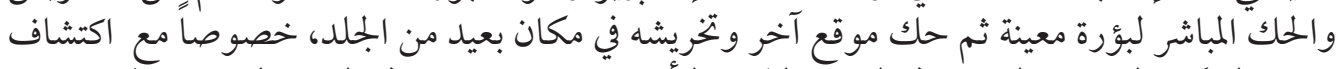

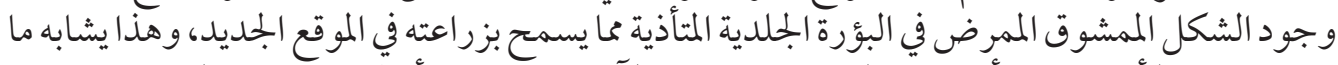

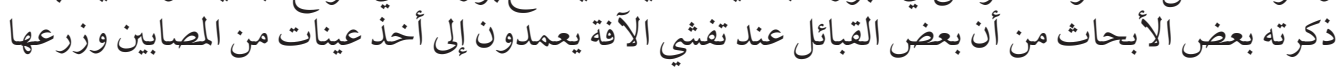

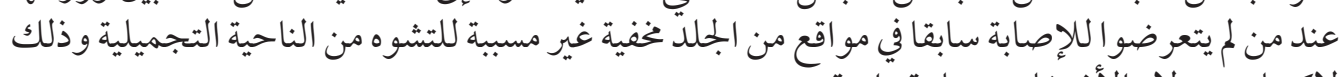
لإكساب هؤلاء الأشخاص مناعة دائمة.

ختاماً

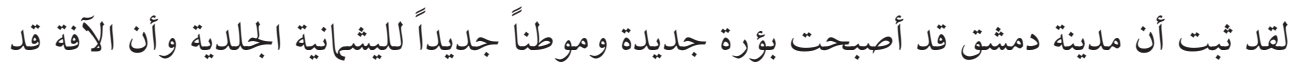

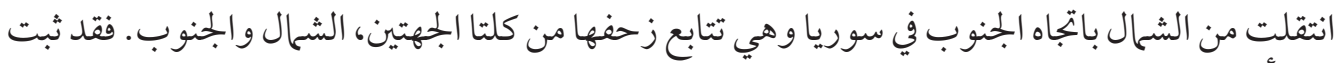

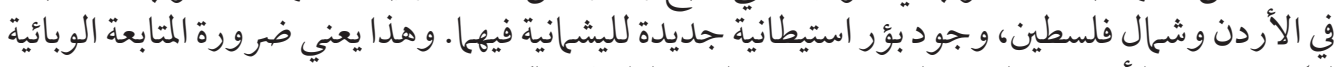

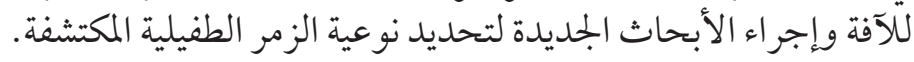

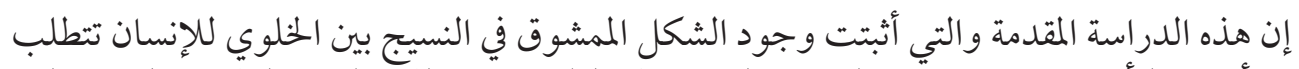

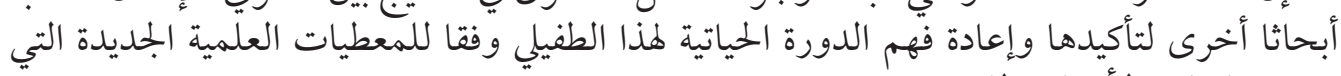

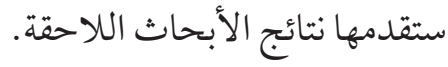




$$
\text { الجلدية التي تؤكد تحول الشكل الممشوق إلى توليد الليف في المراحل المثقدمة من الليشمانيا }
$$
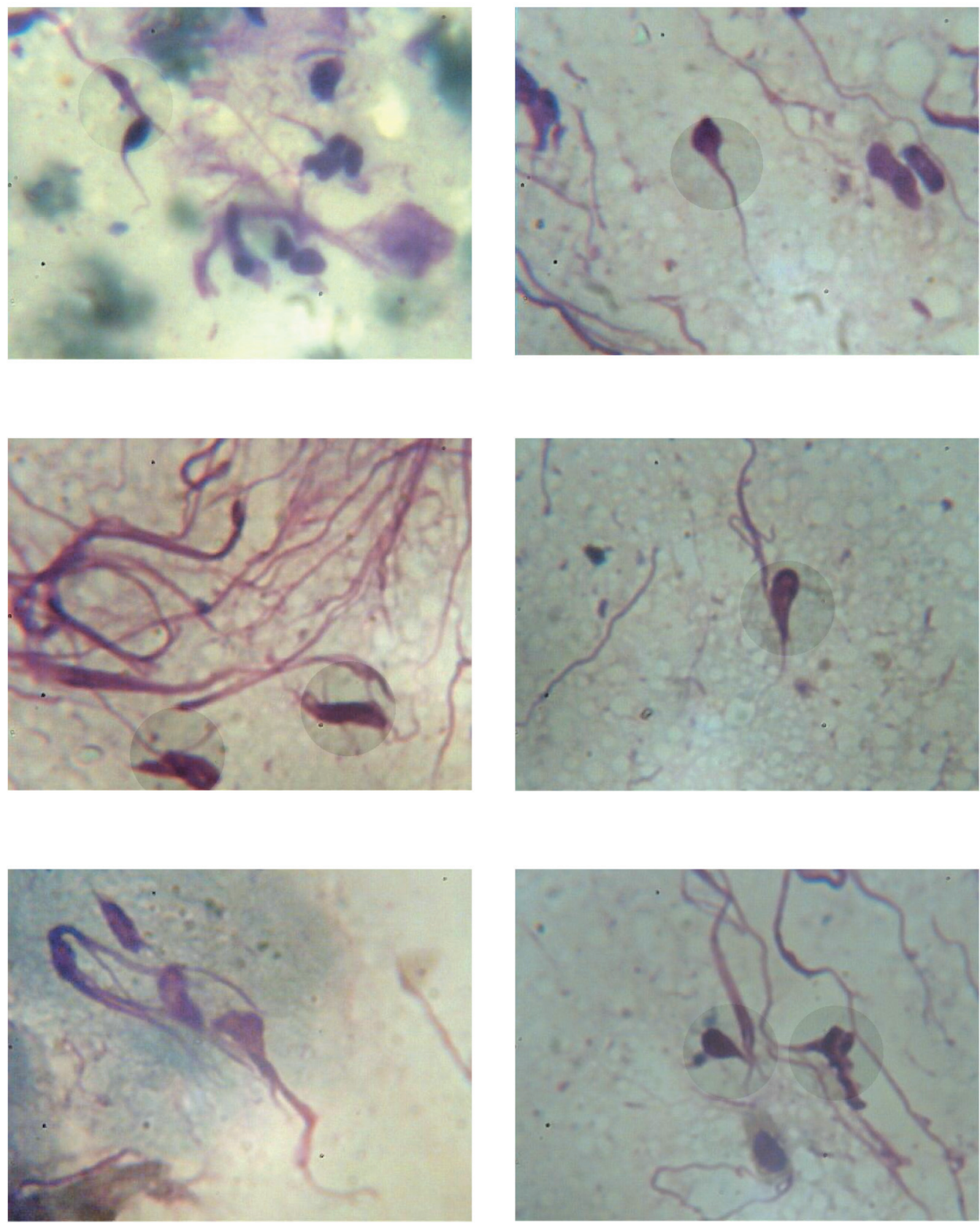

المجلة الصحية لشرق المتوسط، منظمة الصحة العالمية، المجلد الخامس عشر، العدد 0، 9 •. 


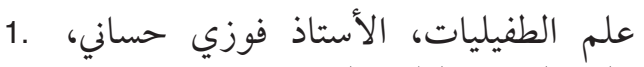
الجزء العملي، الطبعة الثانية 1994-1993 الادينادي

2. Case definition. Cutaneous leishmaniasis. Epidemiological bulletin, 2002, 23(3) (http://www.paho.org/english/sha/ be_v23n3-cutaneous_leishmaniasis.htm, accessed 4 May 2009).

3. Hepburn NC. Cutaneous leishmaniasis: an overview. Journal of postgraduate medicine, 2003, 49(1):50-4.

4. Vidyashankar C, Agrawal R. Leishmaniasis (http://www.emedicine.com/ped/ topic1292.htm, accessed 4 May 2009).

5. Sharquie KE et al. Evaluation of diagnosis of cutaneous leishmaniasis by direct smear, culture and histopathology. Saudi medical journal, 2002, 23(8):925-8.

6. Hepburn N. Cutaneous leishmaniasis. Clinical and experimental dermatology, 2000, 25:363-70.

7. Nimri L, Soubani R, Gramiccia M. Leishmania species and zymodemes isolated from endemic areas of cutaneous leishmaniasis in Jordan. Kinetoplastid biology and disease, 2002, 1(1):7.

8. Leventhal R, Cheadle RF. Medical parasitology, 3rd ed. Philadelphia, FA Davis Company, 1989.

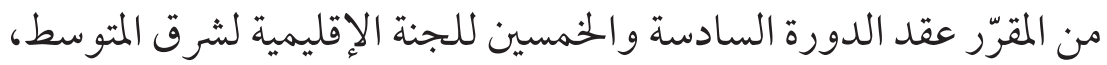

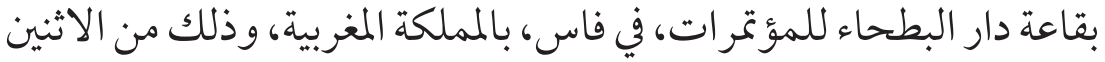

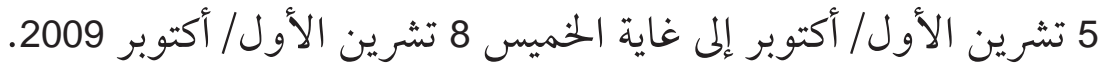

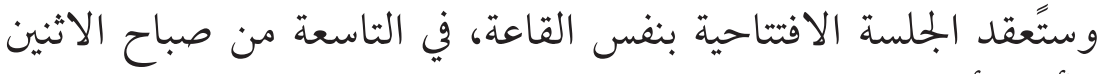
الأول/ أكتوبر 2009 